\title{
¿QUÉ MÁS PODRÍA DARME TU RECUERD0? ACCIDENTE, FOTOGRAFÍA Y ARCHIVO
}

\section{WHAT ELSE COULD YOUR REMEMBRANCE GIVE ME? Accident, Photography \& Archive}

Camila Kevorkian

camilakevorkian@gmail.com Universidad Nacional de las Artes. Argentina

\begin{abstract}
This article outlines possible orientations from where to reconstruct a photographic archive. The aim is to show that narrations are not lineal, not even in the construction and reconstruction of archives. For this, the concepts of realms of memory of Pierre Nora and critical and dialectical genealogy of Michael Foucault are emphasized. As practices and actions that condense this conceptual framework through photography, two works are analyzed: Migront Mourning, Cristian Ochoa's workshop (Chile), and Otsuchi Future Memories, by Alejandro Chaskielberg (Argentina).
\end{abstract}

Keywords

Photographic archive; accident; critical genealogy; discontinuity

\section{Resumen}

Este artículo esboza posibles orientaciones desde donde reconstruir un archivo fotográfico. La idea central es evidenciar la no-linealidad del relato, tanto en la construcción como en la reconstrucción de los archivos. Para ello, se hace énfasis en el concepto lugares de la memoria, de Pierre Nora, y genealogía crítica y dialéctica, de Michael Foucault. Como prácticas y acciones desde la fotografía que condensan este marco conceptual, se analiza Duelo migratorio, taller de Cristian Ochoa (Chile), y Otsuchi Memorias del Futuro, de Alejandro Chaskielberg (Argentina).

\section{Palabras clave}

Archivo fotográfico; accidente; genealogía crítica; discontinuidad 
«Vuestros altares serán arruinados, y abandonados vuestros ídolos, destrozados, desaparecerán.» Ezequiel 6:4

«Sabemos perfectamente que toda memoria está siempre amenazada de olvido, cada tesoro amenazado de pillaje, cada tumba amenazada de profanación.»

Georges Didi-Huberman (2012)

Escena 01: El padre de Nemo sale por la puerta de casa. Al encender el televisor, su padre vuelve a estar ahí, dando las noticias del clima, alentando a sacar las barbacoas al jardín este fin de semana. Escena 02: Nemo y su padre recorren el vecindario y comienza a llover. Los vecinos, a medida que guardan sus barbacoas y sillas, pulverizan con la mirada al padre de Nemo. Nuestro protagonista de siete años se pregunta: «iPor qué recordamos el pasado, pero no el futuro?» (Van Dormael, 2009, 0.20'). La película es una narración no lineal y discontinua que cuenta todas las vidas de nuestro protagonista -la que le hubiera gustado vivir, la que nunca sucedió, la que el azar destruyó-. Un viaje espacio-temporal por los accidentes y por las fisuras de los acontecimientos. Un positivo de la ausencia y de la potencia de ser, o del múltiple haber sido. Después de dos horas y treinta y siete minutos de película, nos quedamos atrapadas en una de las tantas dimensiones que nos propone el film. Nos vemos reflejadas en esos accidentes, en esas fisuras desde las cuales el presente pide a gritos reconstruir nuestro pasado-futuro. Y, sin embargo, una vez encontrada esa posible reconstrucción, esa fisura o ese acontecimiento, no debemos apresarla, tomarla como absoluta ni detener su movimiento, sino ser conscientes de las múltiples direcciones y de todos los elementos que la componen. Michel Foucault (2004) expone al respecto:

Sin embargo, no se trata tanto de encontrar en un individuo, un sentimiento 0 una idea, los caracteres genéricos que permiten asimilarlo a otros -y decir: éste es griego, o éste es inglés-, como de descubrir todas las marcas sutiles, singulares, subindividuales que pueden entrecruzarse en él y formar una red difícil de desenmarañar (p. 25).

En la reconstrucción de un pasado-futuro a través del archivo fotográfico, podemos encontrar, también, las mismas tensiones: una que tiende a lo genérico y a la esencia, y otra singular y de entrecruzamiento. Siguiendo las dos tipologías de archivo que nos propone Anna Maria Guasch (2011), vemos uno que 
ordena y regula, basándose en la homogeneidad y la continuidad, mientras otro, de manera discontinua, propone cambios de secuencia y de sentido. Es esta última propuesta el objeto de análisis y de desarrollo de nuestro artículo.

\section{Construir/destruir: una casa, un archivo, una memoria}

Entendemos por ecosistemo al conjunto de organismos vivos (biocenosis) y el medio físico donde se relacionan (biotopo). El prefijo eco proviene del griego, en el cual oikos significa 'casa'. Llevando estos esquemas al de la memoria, podríamos decir también que ella misma funciona como un ecosistema, en donde elementos inertes y objetos, junto con la acción de los seres vivos, toman diversa forma y significado, en eterna relación e intradependencia.

Pierre Nora [1984] (1992) utiliza la expresión «lugar de la memoria» para definir a cualquier entidad, material o inmaterial, que, a lo largo de los años, se convierte en un elemento simbólico del patrimonio memorial de cualquier comunidad. Esto contemplaría lugares (cementerios, museos, centros de detención), conceptos, prácticas (tradiciones, rituales, memoria oral) y objetos (símbolos, fotografías, pinturas). El historiador explica lo siguiente:

Los lugares de la memoria son ante todo restos, la forma extrema bajo la cual subsiste una conciencia conmemorativa en una historia que la solicita, porque la ignora [...]. Los lugares de la memoria nacen y viven del sentimiento de que no hay memoria espontánea de que hay que crear archivos, mantener aniversarios, organizar celebraciones, pronunciar elogios fúnebres, labrar actas, porque esas operaciones no son naturales (Nora [1984] 1992, p. 226).

Los lugares de la memoria nos mantienen unidos, son restos, ruinas, accidentes, tamizados por experiencias subjetivas, desde los cuales podemos enunciar una de las tantas otras historias. La casa como memoria, la memoria como sistema, el sistema como casa, la casa como lugar de la memoria. ¿Qué sucede cuando nuestra casa se destruye? ¿Qué sistema de orientación podemos generar desde la fotografía a modo de reconstrucción?

La primera vez que Alejandro Chaskielberg llegó a Otsuchi se preguntó cómo podía ayudar a reconstruir la memoria de una ciudad arrasada por un tsunami a partir de un proyecto fotográfico (Zacharías, 11 de octubre de 2016). El tsunami del que nos habla tuvo lugar el 11 de marzo de 2011 en las costas del noreste de Japón y dejó al pueblo pesquero de Otsuchi con el 10\% de la 
población muerta o desaparecida y el 60\% de casas residenciales destruidas. Entre el caos y el desorden, los habitantes recuperaron sus fotografías entre los escombros y el agua e intentaron mantener vivo el recuerdo [Figura 1].

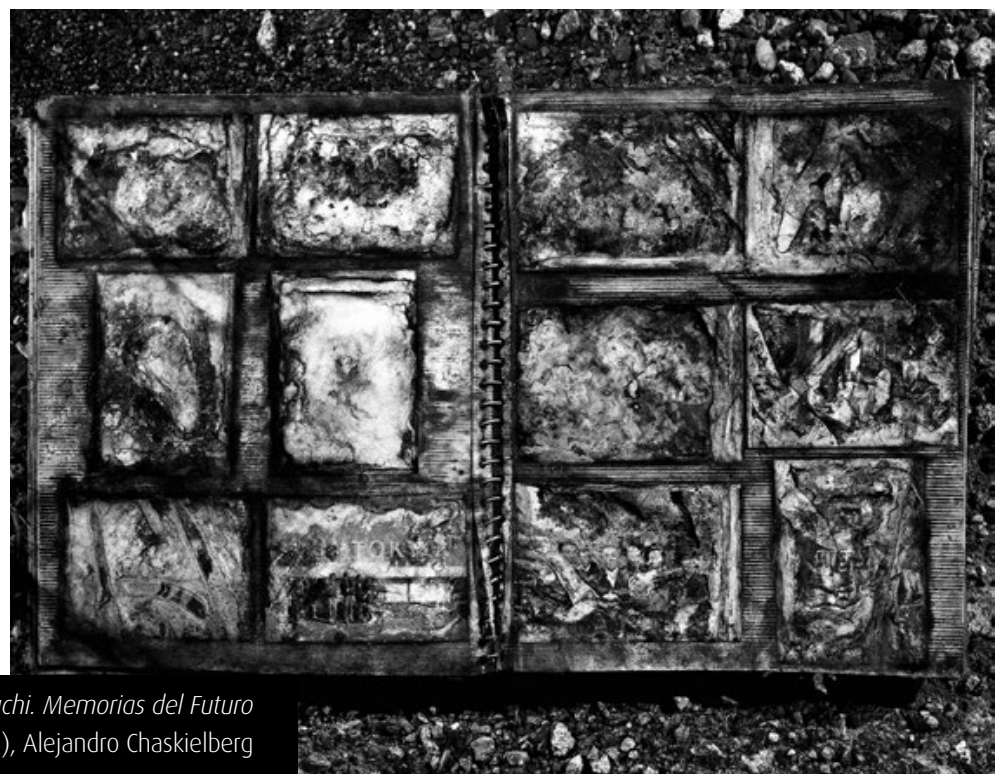

Otsuchi. Memorios del futuro (2015) propone cuatro instancias complementarias y en mutua dependencia desde donde se puede revivir esa memoria. En la primera, se refleja la documentación visual de la destrucción y la pérdida: fotografías de elementos rescatados y deformados por la catástrofe. La segunda conforma el archivo fotográfico recuperado. Los cromatismos posteriores a la sal y los diversos factores climáticos nos devuelven imágenes cuasi radioactivas. Es a partir de estos que el fotógrafo realiza un ejercicio de «arqueología del color», como él mismo denomina; a partir de las dominantes cromáticas de los archivos colorea los retratos de los sobrevivientes [Figura 2]. La tercera parte contempla una arista performática. Los sobrevivientes fueron fotografiados en donde solían estar sus casas y sus trabajos; pusieron el cuerpo en el presente, para revivir y para resignificar un pasado-futuro. No solo se presta el cuerpo por los que ya no están (¿cuántos faltan en ese retrato familiar?), sino que también se presta color al recuerdo. La última parte del proyecto se vincula con el 
hacer: fotógrafas y fotógrafos locales acompañaron a niñas y a niños de entre 11 y 15 años en la tarea de registrar su vida en fotos. Nos dice el fotógrafo: «Las fotografías familiares nos completan, nos hablan de nosotros, son parte de nuestra identidad. Hoy esa pregunta empieza a responderse: hay que actuar en el lugar, devolver las imágenes, compartir y crear juntos» (Zacharías, 11 de octubre de 2016).

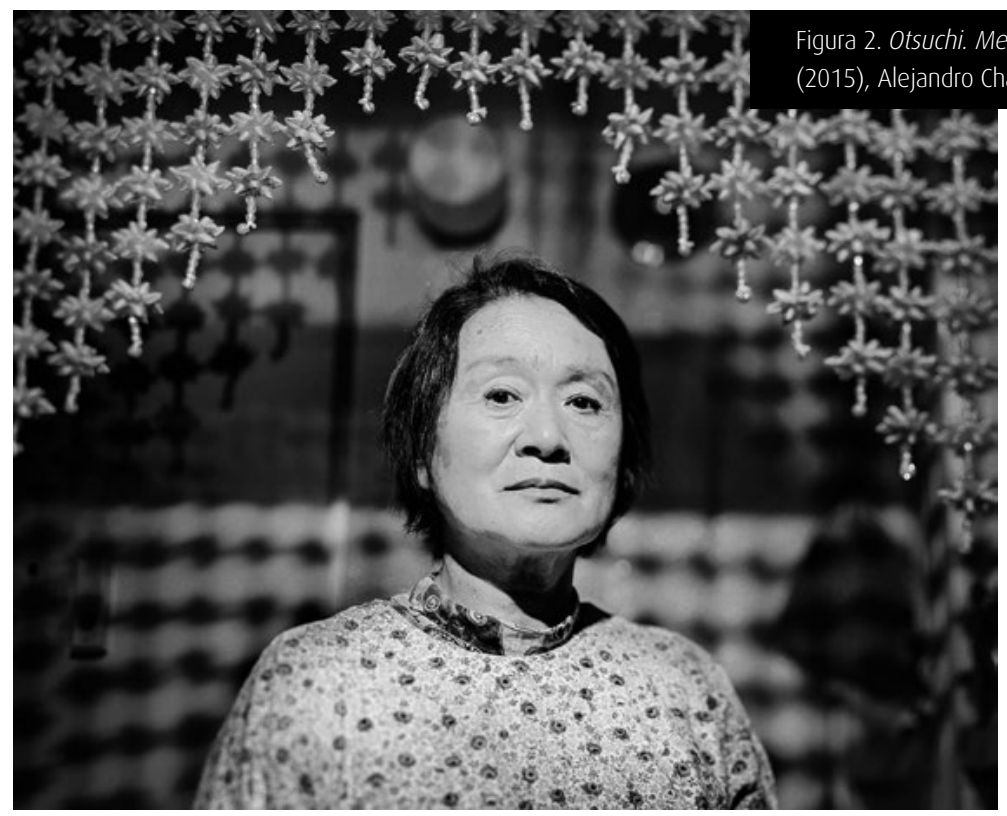

Vemos cómo territorio, imágenes, cuerpo y hacer se combinan para devolvernos un nuevo lugar de la memoria material e inmaterial, presente y futuro desde donde se puede articular y recordar.

\section{Accidente: lo gris, el enunciado y la indeterminación}

Como mencionábamos al principio, la reconstrucción o el recuerdo mediante las discontinuidades del archivo no pretenden llegar al origen, ni mucho menos develar una verdad o una esencia. Un poco porque no existe, otro poco porque tampoco es la función del archivo. Según Georges Didi-Huberman (2012), «el archivo es casi siempre grisáceo, no solo por el tiempo transcurrido, sino 
por las cenizas de todo aquello que lo rodeaba y ardió en llamas» (p. 18). Dicho esto, entendemos que nuestra genealogía, también gris, tiene como meta evidenciar que lo que hoy conocemos y somos no es más que, como dice Foucault (2004) citando a Friedrich Nietzsche, la exterioridad del accidente.

«Accidente» se llama aquello que se da en algo, y su enunciación es verdadera, pero no, desde luego, necesariamente ni la mayoría de las veces. [...] Tampoco hay causa alguna definida del accidente, excepto el azar, y éste es indefinido. [...] Se usa también en otro sentido: así, se dice de las propiedades que pertenecen a cada cosa por sí misma, sin formar parte de su entidad (Aristóteles, 1994, pp. 262-263).

Al hablar de exterioridad del accidente, nos referimos a algo que se manifestó en un momento fortuito, pero no es constitutivo de la sustancia. Pudo manifestarse ese accidente como otros miles, indeterminados e infinitos. Esto sirve en nuestro análisis de archivo fotográfico para entender que la búsqueda de una procedencia no fundamenta ni aclara, sino que «agita lo inmóvil, fragmenta lo que se pensaba unido, muestra la heterogeneidad de lo que imaginábamos conforme a sí mismo» (Foucault, 2004, p. 29). Sirve para entender que si algo fue de tal o cual manera, puede cambiar o redefinirse en cualquier otro momento pasado-futuro. Esta línea de pensamiento, carente de esencia y de determinismo, nos saca el peso de la linealidad del relato y del absolutismo. Entender que lo que nos constituye no es más que la exterioridad del accidente, y que los accidentes se solapan y se reactualizan y, así, permiten recrearnos en el presente desde un pasado-futuro.

\section{Recordar: resistir y reexistir de la imagen}

La segunda práctica fotográfica a analizar es Duelo migratorio. Taller de fotografía intercultural (2016), de Cristian Ochoa, proyecto financiado con fondos del Instituto Nacional de la Juventud (INJUV) en Antofagasta, Chile. Bajo el lema «Construyendo comunidad e identidad en el territorio a través de la imagen», la propuesta reunió a más de veinte jóvenes de entre quince y veintinueve años, originarios de Perú, de Bolivia, de Ecuador y de Colombia. Antofagasta, considerada «La Dubai de Latinoamérica» por su producción e industria del cobre, alberga a más de noventa y seis mil migrantes.

El taller consistió en ocho clases. Por un lado, quienes participaron conocieron y experimentaron diversas técnicas fotográficas (entre ellas, la estenopeica) para hacer tomas de su territorio. Trabajaron con fotografía digital, utilizando celulares para registrar su entorno más íntimo. Además, buscaron en sus 
álbumes familiares, intentando hallar archivos personales, imágenes de parientes, amigos y experiencias vividas que dejaron atrás en sus tierras de origen [Figura 3] (Ochoa, 2016).

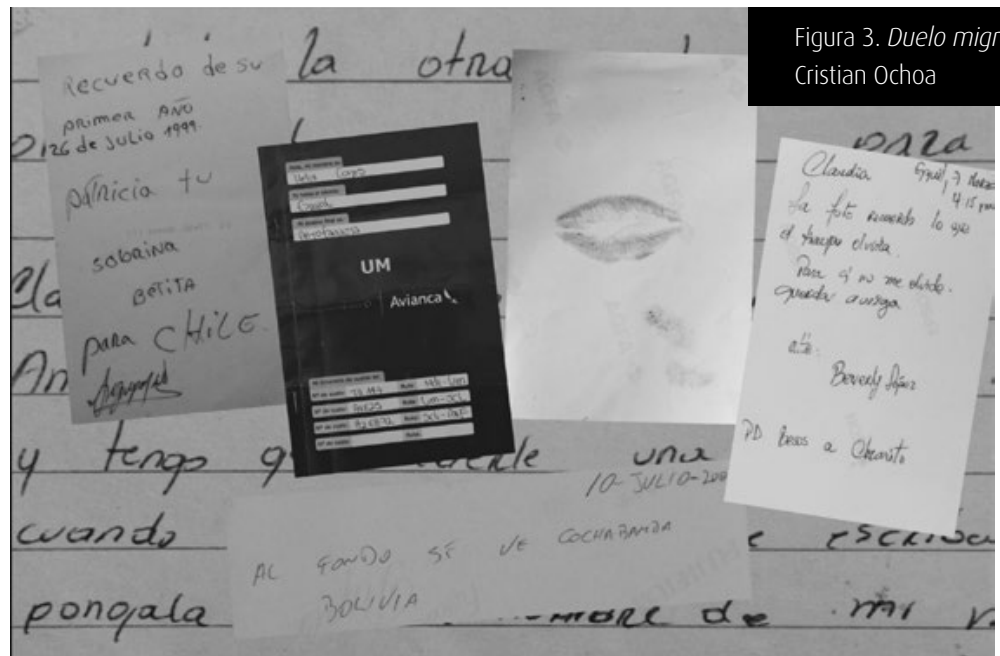

Recordar ese pasado desde la práctica y desde el hacer en el nuevo territorio nos aleja del anclaje absoluto y determinante y nos conecta con la construcción en simultáneo de un futuro al resignificarlo con nuevos accidentes y acontecimientos. Lo reactualiza y lo devuelve al presente de manera crítica y procesual. Como cierre del taller se realizaron intervenciones, bailes típicos de cada comunidad y pegatinas de las fotografías en el barrio [Figura 4]. Vemos, aquí también, la combinación territorio-imagen-cuerpo-acción antes analizada en el trabajo de Chaskielberg.

Figura 4. Duelo migratorio (2016),

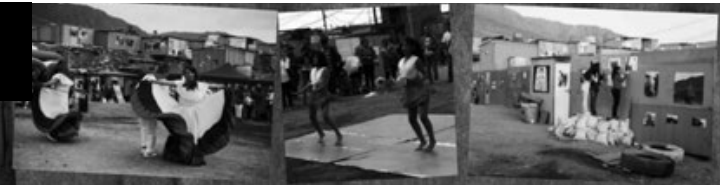
Cristian Ochoa
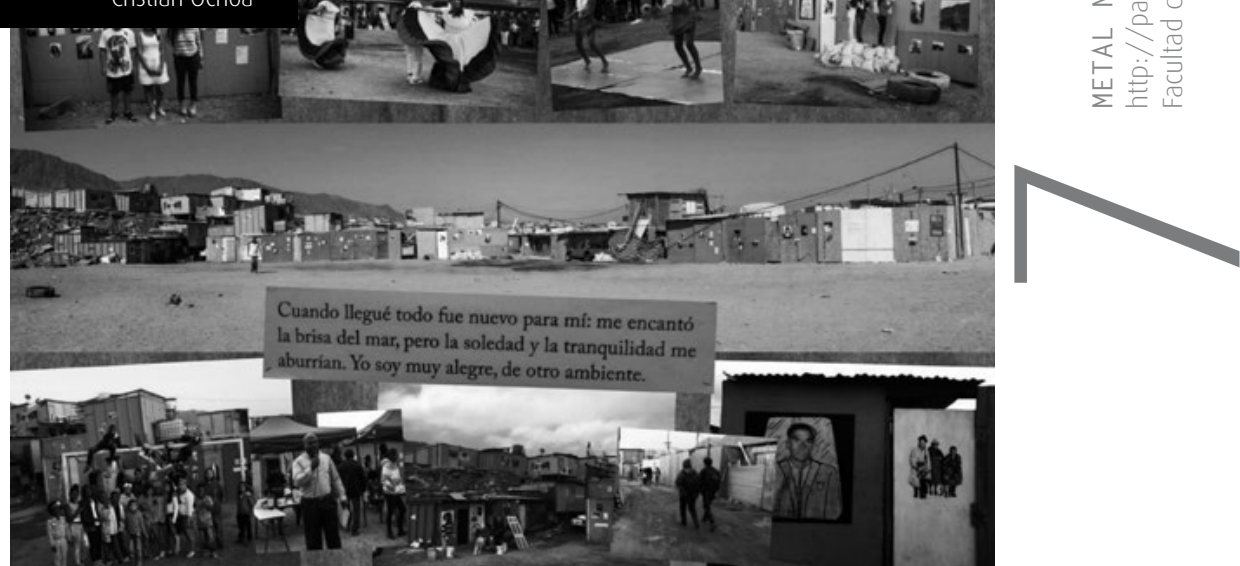
El taller propone tanto fotografiar y recordar como maneras de habitar el territorio, para, desde la emoción y el presente, como diría Nora [1984] (1992), vivir la memoria. Es en esta acción que vemos evidenciado cómo habitar el pasado-futuro desde nuestro presente, tomando como punto de partida al archivo. Por una parte, el taller plantea generar un nuevo archivo. Fotografiar como medio, técnica, recurso y lenguaje desde donde, a medida que se fotografía, se construye, también, un nuevo territorio y nuevas formas de estar en él. Encuadra y se reencuadra: fracciona su interés, sus vivencias, sus amistades, lo íntimo, lo público, lo privado. Por otra parte, propone buscar en los álbumes familiares de quienes participaron. «¿Qué más podría darme tu recuerdo?», se pregunta Julio Cortázar (1969) en un poema, y sirve como título de este artículo. Vemos al archivo fotográfico como un objeto que sana y repone. Si bien la fotografía desde sus inicios siempre estuvo relacionada al recuerdo como presencia, el taller duplica la apuesta ya que es un entrecruzamiento de actuar, vivir, poner y darle un cuerpo a ese archivo; de revivirlo y de reactivarlo por medio del hacer (acción que también vemos en Otsuchi. Memorios del futuro, de Chaskielberg).

¿Qué más podría darme tu recuerdo que poder revivirlo y resignificarlo según mis paisajes y mis territorios? Entender ese recuerdo como otro accidente. Tomar ese recuerdo y abrasarlo/abrazarlo en carne viva, que vuelva a la vida (vida que nunca le fue arrebatada) en cuerpo/forma de un pasado-futuro y se manifieste en el presente.

\section{Conclusión}

Siguiendo esta línea genealógica foucaultiana, que hace hincapié en la ausencia y en los acontecimientos, más que en la evolución y en los hechos, vemos un constante diálogo de tiempos que no son definitivos ni excluyentes. "No hay post ni pre en una visión de la historia que no es lineal ni teleológica, que se mueve en ciclos y espirales, que marca un rumbo sin dejar de retornar al mismo punto» (Rivera Cusicanqui, 2010, p. 54). Desde el presente podemos (incluso debemos) seguir enunciando el pasado-futuro. Hacerlo hablar, usarlo como vía de recuerdo y de memoria, cuestionarlo, situarlo en contexto. Preguntarle a las imágenes deterioradas por un tsunami qué nos quieren decir, qué conlleva esa destrucción. Construir y habitar nuestros nuevos territorios desde la práctica y el hacer, generando nuevos archivos, pero, también, visitando los existentes. Visitarlos y no tenerlos como absolutos ni deterministas, sino como una de las tantas formas y maneras en que se pudo manifestar lo que hoy vemos. Preguntarle al archivo qué fue de los otros accidentes no exteriorizados. Indagarlos, revivirlos, actualizarlos. Hacer una lectura de las fisuras, desde 
el negativo y la ausencia, no desde la esencia, el hecho y lo genérico. Situar nuestros archivos en el territorio, nuestras imágenes en los accidentes, nuestros cuerpos en la ausencia y nuestra acción en lo sustancial será nuestra tarea como nuevos productores de sentido.

\section{Referencias}

Aristóteles (1994). Metafísica. Madrid, España: Gredos.

Chaskielberg, A. (2015). Otsuchi. Memorios del Futuro [Fotografías]. Recuperado de https://chaskielberg.com/portfolios/otsuchi-future-memories

Cortazar, J. (1969) Último Round. Ciudad de México, México: Siglo Veintiuno.

Didi-Huberman, G. (2012). Arde lo imagen. Oaxaca, México: Serieve.

Foucault, M. (2004). Nietzsche, la geneología, la historia. Valencia, España: Pre-textos.

Guasch, A. M. (2011). Arte y Archivo, 1920-2010. Genealogíos, tipologías y discontinuidades. Madrid, España: Akal.

Nora, P. [1984] (1992). Les Lieux de Mémoire. París, Francia: Gallimard.

Ochoa, C. (2016). Duelo migratorio. Taller de fotografía intercultural [Fotografías]. Recuperado de https://issuu.com/cristianochoa2/docs/injuv_4_.compressed

Rivera Cusicanqui, S. (2010). Ch'ixinakax utxiwa: una reflexión sobre prócticas y discursos descolonizadores. Buenos Aires, Argentina: Tinta Limón.

Van Dormael, J. (Dir.). (2009). Mr. Nobody [DVD, video]. Bélgica, Francia, Canadá: Christal Films, Integral Films, Lago Film, Pan Européenne.

Zacharías, M. P. (11 de octubre de 2016). Cuando la vida no es más que una serie de "memorias del futuro». La Nación, p.14. 